\title{
Cycling the Simpson Desert
}

\author{
John R Sutton
}

Having spent most of my professional life in Canada and enjoyed challenges such as the Canadian Ski Marathon, the Nahanni River and climbing Mt Logan - almost annually in the 1970 s - it was hard to work out an appropriate substitute upon our return to Australia. The cross-country skiing is, nevertheless, quite extensive, the rivers especially in Tasmania - can also be challenging. But the mountains are no match for Mt Logan. Still what I needed was something unique.

It was then that I learned of the crazy idea to cycle across the driest, harshest and hottest desert in Australia - the Simpson Desert. The plan was to start on its western edge - almost in the centre of Australia, and travel east to the frontier town of Birdsville in far western Queensland. Yvonne, my travelling companion of nearly 30 years, was again on the go as my support team.

How to prepare? Well that wasn't that easy living in Sydney - a most inhospitable metropolis for cyclists. Still I managed to find a cycleway which enabled me to get to and from work - a distance of $25 \mathrm{~km}$ - so this seemed a good start. That is, until it dawned on me that $50 \mathrm{~km}$ per day on a smooth flat surface in cool weather was really no match for $130 \mathrm{~km}$ per day over a desert track with 759 sand dunes in temperatures reaching the mid 40 s!

In late September we were off to Coober Pedy, recently immortalised by the movie "Priscilla, Queen of the Desert". Then it was Oodnadatta, an outpost famous for its Afghan camel drivers and staging camp for the central Australian desert crossing. Finally we reached Dalhousie Springs, with its thermal ponds, badly needed when the air temperature reached $50^{\circ} \mathrm{C}$. However, the desert is cold at night.

There were 36 entrants in this race and about two thirds were professional cyclists. The rest of the field, like me, were simply doing it "because it was there". Jim and Ron, friends of our daughters (and their ages) were my cycling companions and, not to be put off by the fancy riders in all their finery and high tech bikes and the pretentious team names - Desert Storm A etc, we dubbed ourselves the $Z$ Team.

Well the first day was good and went well for about 30 minutes, when I fell off my bike and
University of Sydney, Exercise Research Centre, PO Box 170, Lidcombe, NSW, Australia 2141

J R Sutton

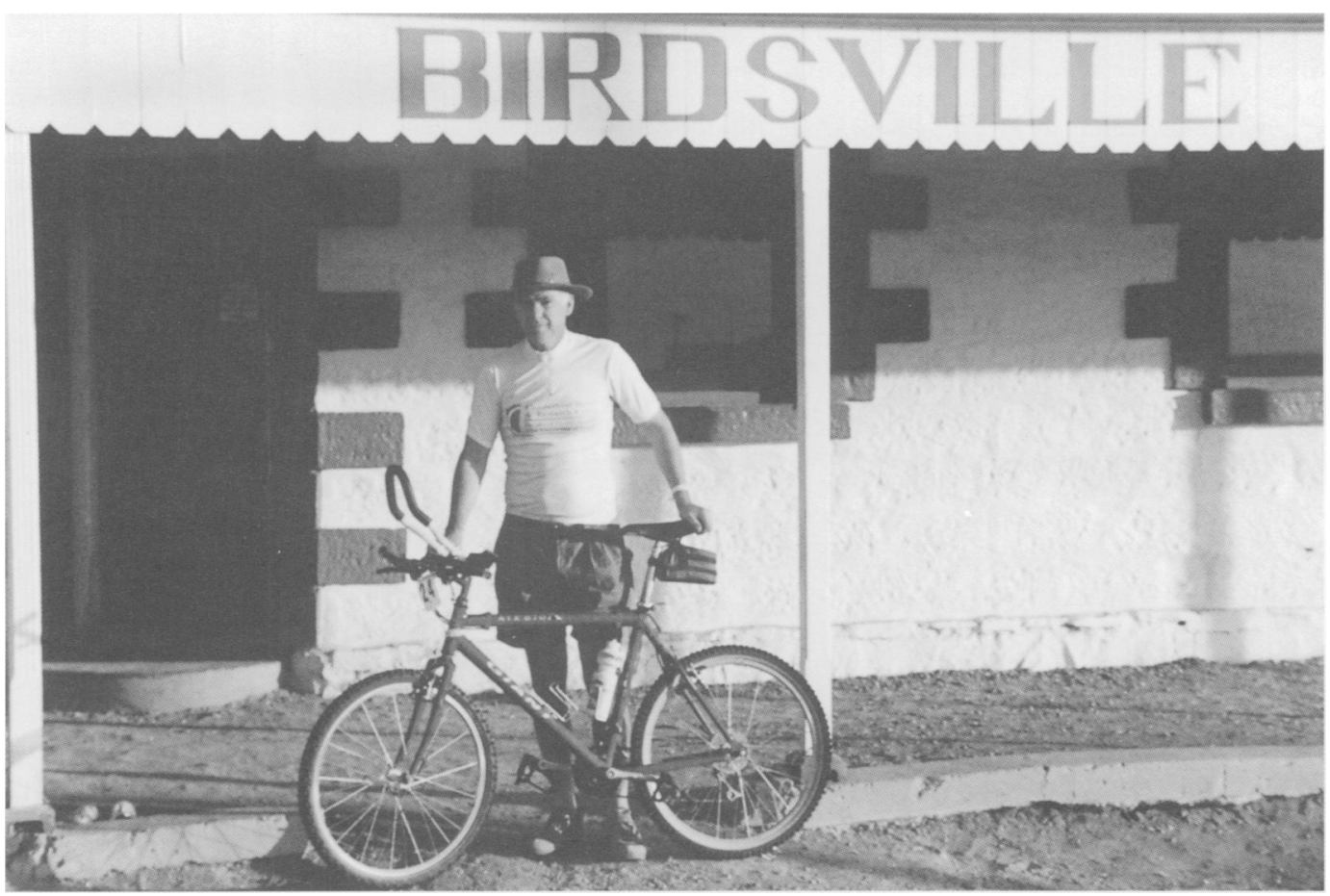


dislocated my thumb (and also fractured it, although this wasn't established till much later).

Day two was the real killer. Only three made it through the morning $80 \mathrm{~km}$ section in the required time and even the real pros suffered; some even pulled out for the rest of the race.

By day three the field was really spread out and most had the scars of a gruelling experience. It was now that the wind came and it was getting hotter.

Day four - the wind worsened, the corrugations got bigger, and about $7 \mathrm{~km}$ from home I got a puncture. I tried to fix it, but with by dislocated thumb, each time I tried to get the tyre back on, the top of my thumb fell off? It just wouldn't work, so I did the only thing left, I ran pushing my bike those last agonising $7 \mathrm{~km}$. Meanwhile my Z Team mates, realising I probably couldn't fix the puncture, waited at the finish line and we all three of the $\mathrm{Z}$ Team crossed the finish line together with only minutes to spare.

Then it was the final day. It was a beautiful dawn and as we began at first light the wind picked up - stronger and stronger until by midmorning it was a full blown desert storm. By now the temperatures were in the mid 40 s. Many dropped by the wayside and the final section was won by Dennis, who had punished himself to the limits - as he crossed the line he lost sphincter control and in the process collapsed into the arms of the welcomers messing not only himself but his welcoming committee also. I didn't go quite that hard, I couldn't afford to lose sphincter control, this desert crossing was part of an environmental study and sphincter control was important as I was monitoring my core temperature rectally!

We actually finished the race $4 \mathrm{~km}$ from Birdsville and then rode together into the full face of the desert storm those last $4 \mathrm{~km}$. The actual finishing spot was the historic 1884 Birdsville Pub. I don't think I've ever enjoyed a beer so much, nor have I been quite so exhausted for many years. After XXXX beer number 4 , all I needed to do was sleep and I did, on the dirt hotel verandah for almost four hours!

What next? Perhaps the Sahara or cycling to the poles! No it's off to Lake Louise and the next Hypoxia Symposium which dates its origin to 1975.

\section{BOOK REVIEW}

Sport, Exercise and Medicine. Edited by $\mathrm{J}$ McCracken and I Williams. (Two volumes, 182 and $172 \mathrm{pp} ; £ 37.50$.). Nottingham: The University of Nottingham, 1995. ISBN 085380448 .

This two volume, multi-authored publication is based upon the teaching programme for the MSc in sports medicine at the University of Nottingham. The scope of the text is the "medicine" of sports medicine, as opposed to injuries. The first volume covers the medical problems in sport and exercise. There are some excellent chapters in this section, with the basic science developed to provide practical advice. I particularly enjoyed the chapter on diabetes and exercise, while those on chest disease, infection, neurology, and neurosurgery are also well written. Not all topics in medicine are covered. There should be less basic science and more advice on who requires investigation for osteoporosis before the comprehensive chapter on the treatment of this condition. I was rather disappointed that "Exercise and the cardiovascular system" concentrated upon the risks of exercise. The benefits for rehabilitation or hypertension were not adequately covered. Fortunately, some dismissive statements were balanced by the chapter on lipid profiles.

The second volume includes rheumatology, disability, and physiology for special groups. The latter section includes children, the elderly, and an excellent chapter on pregnancy. The complex and confusing development of organisation of sport for the disabled is clarified. I am not very happy with the rheumatology section. A chapter on peri-articular lesions falls into the classic trap of failing to look at the sport for the cause and management of injury. There are frequent inaccuracies and it seems to overly encourage steroid injections. I would have liked to have learned about rheumatological conditions and their presentation in athletes. The chapter on joint damage is restricted to a rather biased treatise on the concept of osteoarthritis as a metabolic disease, minimising the effect of trauma.

An added attraction of this book is an interactive quiz. I enjoyed the concept and the quiz. However, some of the answers given are incorrect and I would advise the reader to treat the quiz as an exercise rather than as a source of knowledge.

There is certainly a need for a book to cover this area and the information is presented in a readable style and format. I would recommend the book, but the rheumatology section needs revision.

ROGER HACKNEY Aylesbury, UK 